\title{
WELLBYs, cost-benefit analyses and the Easterlin Discount
}

\author{
Paul Frijters ${ }^{1, *}$
}

\begin{abstract}
The current practise of cost-benefit analysis in Western countries consists of a collection of various incompatible ideas and methodologies to obtain replicable numbers for the costs and benefits of major public spending plans. This paper describes the main elements of the dominant methodology, which combines consumer and producer surplus, price-taking, government-inputs-as-outputs, hedonic pricing of externalities, and the issue-specific use of partial or general equilibrium thinking. The paper then discusses how that methodology can be augmented and partially replaced by looking at how prospective policies would change the total number of WELLBYs (life satisfaction-adjusted years of life) of the population. The ability of the WELLBY methodology to address complex externalities is illustrated by the Easterlin Discount, which is a proposed reduction factor of $75 \%$ on all estimates of private consumption benefits to offset the envy caused in others.
\end{abstract}

Keywords: cost-effectiveness; wellbeing; consumer surplus; Easterlin Discount; public advocacy

\section{Introduction}

Cost-benefit analysis (CBA) has been used for over a century in Western countries to assess whether large projects are worth doing. Dupuit (1848) is said to have initiated this approach in the 19th century when he proposed a specific methodology for looking at the social spending case for building a new bridge in France.

In the UK, the ministry of finance, known as the Treasury, has stated that other ministries and agencies should use some form of CBA when seeking public funds. The Treasury Green Book (2018), which has been maintained and updated by departments for decades, lays out the basic methodology for doing so. Moreover,

\footnotetext{
${ }^{1}$ Department of Social Policy, London School of Economics, London, UK

${ }^{*}$ Correspondence to: Paul Frijters, p.frijters@1se.ac.uk
} 
dozens of additional publications by individual departments specify the CBA methodologies that should be applied for particular purposes. For a general text on cost-benefit analysis as it is applied in broad terms throughout the world, see Boardman et al. (2017, 4th Edition).

The reality of how funding is approved is, of course, not that simple, as many large-scale policies are driven by politics. Nonetheless, it has been a long-standing aim of the UK Treasury to move increasingly towards a world in which large public expenses have to be justified on the basis of some measure of what the gains and the costs of such policies are. The same pressures can be found in most other Western countries, as the approval of infrastructure projects in particular is almost always preceded by a cost-benefit analysis.

When performing a cost-benefit analysis, it would, ideally, be possible to understand everything about the world, and to thus be able to say with perfect foresight what the investment would change. Again, this is too much to ask. The practise of cost-benefit analysis resembles a leaking bucket cobbled together from different intellectual traditions and pragmatic considerations.

Nevertheless, this leaking bucket is the main tool our societies have to assess what matters to the government; i.e., its goal function. A point that is seldom noticed is that the rules of thumb and habits of accounting represented in government costbenefit analysis serve as de facto measures of forms of welfare that our societies strive to maximise. Loosely speaking, it is the notion of economic surplus that Jules Dupuit envisaged.

As a measure of what matters, economic surplus is wholly inadequate. Many things that people care about and spend resources on, such as their children and the quality of the environment, are not naturally part of economic surplus. Thus, CBA analyses have adopted numerous ad hoc assumptions in an effort to capture some of its value. Many things that governments spend resources on are not based on any CBA, nor could they be determined by a CBA. For example, questions like how large the army should be or how the tax authorities should be organised cannot be determined by a CBA. While models that calculate the costs and benefits of these issues can be envisaged, they do not exist in reality. In weighing these questions, political judgment and organisational learning are relied upon instead.

In this piece, I first provide a simple account of what cost-benefit analysis entails in Western countries, and then propose an alternative measure of welfare: the stream of WELLBYs of the entire population of the country. A WELLBY is one unit of life satisfaction on a $0-10$ scale for one person for one year (introduced in Frijters et al. 2020). While I advocate using the WELLBY as a replacement for economic surplus, I show how it can also be used as a patch for some of the problems with existing CBA analyses. In particular, I introduce the idea of the Easterlin Discount, which can be applied to all private economic surplus in order to account for consumption externalities. The idea is that the private consumption of someone else creates jealousy and envy in others, which leads to the need to only count a proportion of the private consumption benefit as social benefits. The proportion that needs to 
be discounted is called the Easterlin Discount, introduced in Frijters and Krekel (2021).

To explain the practise of CBA in the UK, I first set up a standard CBA calculation loosely based upon the extension of Heathrow in the UK (which was actually proposed as a project by the Airports Commission 2015). I use this example to explain the leaky bucket of the current approach to CBA. Then, I introduce the alternative, the WELLBY, and show how it can be used to either replace the bucket entirely, or as a patch for particular problems.

\section{The practice of CBA in the UK}

Here, we refer to the practise of CBA in the UK. Each Western country has subtly different habits in the use of CBA. Hence, the observations we make about the UK will not perfectly hold for other countries.

Consider Table 1 below, which is partly populated by the actual numbers from a government-commissioned report by the Airports Commission (2015), and partly consists of made-up entries (regarding health quality-adjusted life years, QALYs) that are included to illustrate further aspects of the practise of CBA.

This table illustrates four elements involved in standard cost-benefit analyses that are, on closer inspection, unexpected and incompatible. Let us examine these four elements in turn.

\subsection{Consumer surplus}

The big positive element in the first column, worth $£ 54.8$ billion, is the supposed consumer surplus of the additional runway at Heathrow. While this number comes from a model, at its core, the calculation comes from the estimation of demand curves. To remind the reader: consumer surplus is the difference between the willingness to pay and the price of something, and thus indicates how much additional money a person would have been willing to pay to buy something.

What is crucial to realise is that consumer surplus is not actually observed. It is not the production or the price of a traded good; instead, it is some notion in the head of the consumer of the utility he or she would enjoy by consuming a good, versus the price of that good. Hence, it is a psychic good that is not part of GDP or some other notion of national income, but is nonetheless valued in terms of money.

Thus, the inclusion of consumption surplus in cost-benefit analyses indicates that the government economists who run CBA believe in unseen pleasure and the value of traded goods, which they measure by figuring out what individuals were willing to pay for a good versus what they actually paid for it.

This is also the approach that "CBA people" prefer to use to value everything, whether it is the environment, sex, noise or democracy (Boardman et al. 2017 or 
Table 1:

Appraisal results for the Heathrow Airport Northwest Runway scheme, present value (£billion, 2014 prices). 50\% Easterlin Discount and rearranged

\begin{tabular}{|c|c|c|}
\hline \multirow[b]{2}{*}{ Appraisal results } & \multicolumn{2}{|c|}{ With or without Easterlin Discount (ED) } \\
\hline & Without ED & With ED \\
\hline \multicolumn{3}{|l|}{ Monetised } \\
\hline Consumer surplus & 54.8 & 27.4 \\
\hline Producer surplus & -38.4 & -19.2 \\
\hline $\begin{array}{l}\text { Scheme capex and private paid } \\
\text { surface access cost }\end{array}$ & -13.6 & -6.8 \\
\hline Primary surplus change & 2.8 & 1.4 \\
\hline Delays & 1 & 1 \\
\hline Wider economic impacts post-tax & 6.9 & 3.45 \\
\hline Noise & -1 & -1 \\
\hline Air quality & -0.8 & -0.8 \\
\hline Carbon emissions & -0.9 & -0.9 \\
\hline Biodiversity & 0 & 0 \\
\hline Health costs $(100,000$ QALY) & $-6,0$ & $-6,0$ \\
\hline Government paid surface access costs & -2.5 & -2.5 \\
\hline Taxes $(40 \%)$ from wider economic impact & 4.6 & 4.6 \\
\hline Government revenue & 1.8 & 1.8 \\
\hline NPV (net social benefits and PVC) & 5.9 & 1.05 \\
\hline \multicolumn{3}{|l|}{ Non-monetised } \\
\hline Surface access & Light green & \\
\hline Quality of life & Neutral & \\
\hline Community & Light red & \\
\hline Place & Light red & \\
\hline Local economy & Dark green & \\
\hline Water and flood risk & Light red & \\
\hline
\end{tabular}

Note: $\mathrm{NPV}=$ net present value, $\mathrm{PVC}=$ Present Value Cost.

For the moment, we ignore the distinction between the first and the second column, because the Easterlin Discount will not be explained until much later. Instead, we look purely at the first column (the "without ED" column).

Campbell and Brown 2016): i.e., they look for some way to measure what people's willingness to pay for something is (often by asking them about their willingness to pay in a survey), and then they look for an appropriate price so that they can calculate the consumer surplus involved. 
There are many hidden value judgments in this practise. Let me list four of the main ones:

1. The economic surplus of every person is added up as if who does the consuming was unimportant. This simple process of adding up is used partly by necessity, since it is often not known who buys a good. Hence, it is not possible to "correct" for how rich or poor the person is. This means, however, that the rich person generates far more consumer surplus than the poor person, and thus counts far more than the poor person in cost-benefit analyses. It is the equality of every pound, not of every person. Thus, economic surplus is deeply anti-democratic. Moreover, it does not conform to any normal economic notion of "utility", i.e., the amount of psychic benefit, because that utility would then, of course, have to be measured. We can therefore conclude that the concept is based largely on convenience, and the need to get a number.

2. It is assumed that consumers know the full costs and benefits of their consumption, such that everyone who consumes is enjoying a surplus, and there are no systematic mistakes. Hence, there is an untested presumption of consumer rationality and responsibility in CBA: i.e., that there are no regrets of any kind.

3. The consumption of a good is seen as a stand-alone purchase that is not connected to other purchases, such as when an airline ticket is only part of a whole consumption package ("the trip"). This stand-alone assumption means that the surplus of the whole trip is assigned to an individual element of it, while the same surplus can also show up in different calculations involving elements of the package (like the hotels and the attractions consumed on a trip). Thus, it is assumed that consumers are not able to obtain the same economic surplus with some other purchase; i.e., that there are no other goods in the economy on which a surplus is based. The partial equilibrium assumption embedded in models of a single sector implies, for example, that there is no opportunity surplus that is foregone when a consumer buys an airline ticket. There is a deliberate one-sided blindness to this assumption that inflates the supposed social value of consumption increases, and that is again basically made for the sake of convenience.

4. It is assumed that there are no consumption externalities between individuals: e.g., that no one else loses or gains if air trips are made. This is unwarranted, because individuals will usually travel somewhere to meet other people, thereby creating a positive externality for those other people. A husband who is travelling to meet his wife will, presumably, create surplus through his wife as much as through himself. By ignoring such externalities, social life is implicitly assumed to be of no importance. This observation also applies to negative consumption externalities, like jealousy. It is, for example, assumed that no one is made to feel inadequate if other, richer people fly around all the time. This, too, is unlikely. 
Thus, I argue that the practise of estimating and counting consumer surplus has no obvious "economic foundations", and that it does not take into account social life, issues of inequality, general equilibrium or limited rationality.

Nonetheless, CBA is a very powerful approach that can assign numerical values in many cases. For anything with observed market prices and some history of demand curves, CBA can be used to estimate changes in consumer surplus if capacity is increased. That is why consumer surplus is a cornerstone of CBA around the world: it is a concept that can be applied to generate numbers. Whether the numbers are reasonable or nonsensical cannot be known unless we are able to measure the underlying pleasure that consumers derive from the consumption of the goods in question. These numbers meet the needs of a CBA industry that has to come up with non-negative numbers that demonstrate how much an expansion of the consumption possibility space would benefit consumers.

Another important advantage of the notion of consumer surplus is that the procedure used to obtain a given number is replicable, and would yield the same number if someone else followed the same procedure. This makes it possible to defend the number on the basis of a list of assumptions included in the model that estimates the demand curves and other aspects of the problem. Thus, the number is defensible and replicable, which are very important qualities from the perspective of bureaucracies.

We will encounter this dynamic frequently when considering how CBA is applied. The driving logic of many aspects of CBA is the need to come up with a number that others would also come up with if they used the same "accepted procedure".

Let us now turn to the next number in Table 1.

\subsection{Producer surplus}

The next number in Table 1 is the anticipated change in producer surplus, estimated as a negative value of $£ 38.4$ billion. This number seems more straightforward, as it represents the anticipated reduction in the profits of airlines due to the anticipated lower prices following an increase in the possible number of flights to Heathrow. This figure is a combination of lower profits on existing flights and low profits on additional flights.

On closer inspection, however, this number is indefensible, primarily because the airline industry is a highly competitive sector in which almost no profits are made (Morrison and Winston 2010). If there are no profits, the claim that $£ 38.4$ billion can be subtracted from profits is false. It is worth noting that if airlines were truly forced to reduce their earnings by that much, they would either go bankrupt or stop flying to Heathrow. Thus, this number does not make much economic sense.

Though indefensible, there is an important effect of the claim that consumer surplus is highly positive whilst producer surplus is highly negative: it makes the proposed runway look like a good deal for consumers. Thus, consider the conclusion 
of the Airports Commission (2015) report, which makes the following observation on the basis of these numbers:

"Against the objective of maximising economic benefits and supporting the competitiveness of the UK economy the Heathrow Airport Northwest Runway option performs most strongly, generating $£ 69.1$ billion of benefits, compared to $£ 58.7$ billion from the Extended Northern Runway scheme and $£ 60.1$ billion from the Gatwick Second Runway".

Hence, the report notes that this figure is based almost entirely on the supposed consumer surplus, which it calls an "economic benefit", even though it is not a number that refers to GDP. Thus, it puts weight on what is a metaphysical number (an unseen psychic benefit presumed to be revealed via willingness to pay) that is more closely aligned with psychology than with economics.

Deep within the report we find the information on what is actually likely to happen following the airport expansion: namely, that prices will not drop at all for consumers because it is anticipated that the regulator will allow price increases. The report thus states on page 89 that "the airport scheme would be financed privately and offset via rising aero charges levied on the passengers and users of the airport (not accounted for in this calculation)".

Thus, the profits of the airlines will not suffer after all. Instead, the airport will simply attract more business, which is why the airport operator commissioned the modelling, and is pushing for this additional runway. Heathrow commissioned the modelling that led to the high estimated consumer surplus. And yet it appears that the airport operator wants to convince the reader that the producers are going to lose nearly $£ 40$ billion.

So the headline numbers have been twisted to appear as if the consumers, rather than the producers, will win out. This is done by not using the actual anticipated prices in the calculations. It is a straightforward case of cheating: one cannot say in the main conclusions that the airport expansion is good for consumers, and then say in a passage hidden deep in the report that one actually expects a totally different consumer surplus (via a higher price) than the surplus that is used to come up with the main conclusions.

Thus, on closer inspection, we can see that both the consumer surplus and the producer surplus are essentially hoaxes; that is, they are the products of political posturing meant to convince politicians and consumers of the advantages of building a new runway. While the Airport Commission is supposedly independent and on the side of the British public, it is clear that it has been captured by vested interests. This is hardly surprising, given that cost-benefit analyses are typically paid for by stakeholders with the expectation of private gain. Bureaucracies want CBA to be performed because they want it to appear as though the decisions are made based on scientifically credible numbers. Meanwhile, interest groups want projects from which they expect to earn a profit to go ahead. Those interest groups then simply make up the numbers the bureaucrats need, while pursuing their own objectives. 
Similar objectives can be discerned when we look at the "scheme CAPEX..." number, which supposedly denotes the direct costs producers would have to pay to build the additional runway. In addition to being inflated, this number hides the fact that the government usually pays a substantial share of these costs. The government may, for example, help to cover the costs of building the infrastructure and of buying the land. This point was also conveniently hidden in the report, because in the appendices of the report it is revealed that the government usually pays half the access costs.

The strategic forms of miscommunication detected in this Airport Commission report are not, of course, replicated in all CBA analyses. But the way in which changes in producer surplus are calculated in the report is indicative of how this is done elsewhere. The important elements of this calculation are as follows:

1. The prices and costs for producing something are taken as given, and are thus not subject to negotiation. This often means that the government is expected to pay high prices for something it could get much cheaper. The producer surplus calculations are based not on the lowest price the government could achieve, but on the price demanded by private companies. This might have been reasonable when a town was building one bridge in France in 1848, but it is not reasonable today. The government is not a price taker, and should not make the mistake of acting like one.

2. In most cases, there are many elements of the costs of producing something that involve the government, either as the source of the money or as the regulator. For instance, the runway cannot be built unless the government uses its power to force everyone living on that land to sell their property for a particular price. Moreover, a wide range of utility and infrastructure services are involved in an airport expansion, such as water and electricity supply and transport to the extended airport. Providing these services also involves a great deal of government investment and regulation. Judgment calls and agreements on all these services are also part of the actual costs and benefits, but unless the entity drawing up the CBA is very honest and independent, it is very easy to understate the true costs of the project to the government: only real experts would notice the subterfuge.

Thus, the producer surplus line in this table, which is really the main "cost" line, is, in fact, a reflection of the outcomes of lengthy negotiations and choices by governments in the coming decades. One of the main drawbacks of CBA is that it does not automatically make negotiations and regulation part of the process by, for example, informing the government of the cost savings that can be achieved via optimal negotiations and regulations.

The very notion of calculating a cost and a benefit has within it the presumption that the costs can be known. However, these costs cannot be known if they are the outcomes of strategic negotiations with large private parties. Here again, we see that CBA is not aligned with many aspects of economics. We also find that simply taking the prices named by producers as a given makes for verifiable numbers. Although 
this is not standard economics and makes for irrational government, this approach is a more easily replicable bureaucratic procedure.

Let us now go on to a third important aspect of CBA, which is how it treats government revenues versus private surplus.

\subsection{Government revenue and private surplus}

There are four lines in this table that involve government in relation to the private sector. Let us take them in turn.

First, we look at taxes ( $£ 4.6$ billion) and government revenue ( $£ 1.8$ billion). The crucial point to note is that these figures are simply added up together with the private economic surplus, regardless of whether they represent the consumer surplus or profits.

While this may seem like an innocuous thing to do, especially as it is the standard used in nearly all government CBA, it is actually quite strange. The presumption is that the value of what the government does is exactly equal to how much revenue the government collects via taxation and other sources (such as from the sale of land).

Hence, it is assumed that the government generates no surplus of any kind. The implicit model of the world is thus one in which the government is practically useless. Indeed, since consumers would enjoy a greater consumer surplus if they had additional resources, the government is assumed to be worse than useless, as the taxes paid to the government represent net losses to society - at least according to CBA.

Obviously, this assumption is not based on economics. So where does it come from?

It seems to come from GDP accounting, which also adds up government spending and private consumption as part of national consumption. Within GDP, which does not measure the pleasure from consumption, but simply adds up everything with a market value, government activity is valued as equal to its costs (inputs are outputs). Thus, the CBA practise seems to consist of just adding private economic surplus together with government revenue.

Yet, as we saw in the case of consumer surplus, CBA does not measure the change in GDP, because it would otherwise not include the difference between the willingness to pay and the price as part of its calculation.

Note also that it makes life easy for the CBA calculator to simply assume that the value of any change in government revenue is exactly equivalent to that change: i.e., there is no need to understand what government does and might or might not add. Once again, we see that CBA is a highly verifiable way to come up with a number for the value of government activity.

But is it remotely reasonable to assume that government spending would generate no surplus? Basically, the answer is: "Not at all". Governments run many monopolies that make it a relatively cheap provider of services. The education and health services provided by the government are far less expensive than those provided by 
private firms, and they frequently deliver better outcomes. There is, for example, evidence that private health provision in the US is more expensive and has worse outcomes than European systems (Papanicolas et al. 2018).

We also have ample evidence that government services are highly effective when they are first set up. When Turkey rolled out its General Practitioners (GP) services, each doctor was estimated to save about half a life for every year of practise (Cesur et al. 2017), which is a hugely positive surplus. Economic historians similarly credit the large increase in longevity to government investments, including investments in sewage, inoculations, food safety and cheap transport (Smith 1999).

Is there any empirical evidence that government spending is useless? Most estimates show that government spending is, on the contrary, highly effective. A key number that can be cited in making this case is that according to its internal calculations, the UK government estimates that it produces a year of high quality life for every $£ 15,000$ spent on health services. It has also estimated that the equivalent costs of consumers buying a QALY on the private market is $£ 60,000$ (see Department of Health Report 2019). Thus, the UK government assumes that it is four times as effective at producing QALYs as the private market is when it comes to health.

There is also an inherent contradiction in assuming that the government is useless in a CBA, as the whole point of a CBA is to convince the government that a project is worth undertaking, based on the premise that goods that produce a positive surplus should be funded and organised. How is it possible to simultaneously assume that the government has the capacity to judge the CBA under consideration, but that all other activities funded by the government are useless?

These assumptions seem even stranger if we reflect on another number in this table: namely, the number denoting the supposed value of 100,000 QALYs generated by the project. This number is not in the Airport Commission report, and I added it purely to illustrate a point. It is intended to reflect how within the UK government's machinery changes in health are now valued: any health benefits (or disbenefits) now have to be valued at $£ 60,000$ per QALY generated or lost. Thus, the assumption is that individuals are willing to pay $£ 60,000$ for an additional high quality year of life, whereby high quality is thought of purely as a high level of health.

Therefore, QALYs are valued at $£ 60,000$, if generated by a project. However, at the same time, the government itself calculates that it can produce a QALY at a cost of $£ 15,000$. This is obviously incompatible with the idea that the net added value of the whole of government is zero.

These three incompatible prices lead to a number of incompatible implications when taken to their logical conclusion.

One implication is that the government is assumed to be able to "print surplus" by usurping all of the resources involved in a project, and can simply spend these resources producing QALYs. Basically, it is assumed that the government makes a surplus of $£ 4$ for each pound of investment in health. 
Thus, if CBA were taken seriously and to its logical conclusion, the benefit-tocost ratio of any project should be at least four for the government to prefer it to spending more tax revenues on health production. The fact that this is not actually the case means one of two things: either the government does not actually take CBA seriously at all, or all government spending has an equal multiplier in its benefits that implies that it should not spend all tax revenues on health services.

There are more impossible implications of these price inconsistencies: if we assume that health spending has a four-to-one cost-benefit ratio, but total government spending is worth exactly the same as the inputs, the implicit assumption is that non-health spending has less value than its costs. Since health spending in the UK is about $25 \%$ of all government spending, the health spending alone is worth the full value of all government revenues. Thus, logically speaking, all other government activities are assumed to have a value of zero: i.e., they destroy the surplus, as if all other government activities benefit no one, not even a fraction of the inputs.

We can therefore state that the trifecta of assuming that individuals are willing to pay $£ 60,000$ for a QALY, that governments produce health at a cost of $£ 15,000$ per QALY, and that government revenue has the same value as consumer surplus, are inconsistent. These assumptions imply that government is both useless and four times as useful as consumer surplus.

This point might be dismissed by noting that health has a special status within the UK government, and that the convenience of making mutually incompatible assumptions - which has been common practice for the last 10 years - protects the health budget from cuts, and makes every other ministry and large organisation keen to count health benefits and avoid adverse health consequences. Thus, it is possible to argue that even though it is clear that cost-benefit analyses involving health are nonsensical, their use leads to better incentives within different departments and organisations relative to some prior status quo. This may be true, but the use of CBA also leads to perverse incentives, as any ministry can make any project look good by also producing some health benefits at a cost of $£ 15,000$ per QALY, while claiming that they are worth $£ 60,000$ per QALY. It therefore appears that any bad project can be made to have a high net present value by including some health expenses. The health ministry in the UK now uses exactly that trick in many cases (see, for example, Department of Health Report 2019).

Moreover, I should briefly note that the labour market benefits of the airport expansion plan - i.e., the additional jobs - are valued using general equilibrium arguments, which is to say they are not valued at all. In the UK, additional jobs only count in CBA if the case can be made that these individuals would otherwise remain unemployed. To do so, it would be necessary to argue that jobs are created faster in the industry related to this project than in the rest of the economic sectors. Hence, when it comes to the labour market, general equilibrium thinking is enforced, while for most other purposes, general equilibrium thinking is avoided. One for instance cannot interpret the consumer surplus estimates in a general equilibrium way: they would then be meaningless. 
Finally, we should briefly mention that in Table 1 , various externalities like noise and biodiversity are listed. These have been valued by generating an as-if willingness to pay a certain number, either by presenting people in the neighbourhoods with a scenario in which they have to choose between having less money and greater biodiversity; or by making hedonic calculations, such as by inferring a low willingness to pay for noise by the low degree to which noise is reflected in house prices. Thus, again, a rather extreme version of rationality is used to generate rather low numbers for the costs of noise and biodiversity. If the report had instead used the actual estimates of the health costs of noise, or of the production costs of more biodiversity (e.g., Stansfeld and Matheson 2003), the numbers would have been far higher. But then, the airport expansion would have been rendered much less attractive.

The final point is, therefore, that the absence of a standard and accepted measure for valuing non-market goods like noise and biodiversity allows CBA calculators to choose from a wide range of methods. Obviously, they then choose the method that makes those who pay them look good.

\subsection{Summing up the practise and problems of standard cost-benefit accounting}

As practiced in the UK, CBA is based on a very odd collection of mutually inconsistent assumptions. To sum them up:

1. It adds up private consumption and government revenue, thereby copying the GDP accounting practises of the 1940s.

2. Since about 2010, health benefits have been counted as four times as much as the government production costs of health. Together with (1), this basically means government is assumed to be both useless at anything but health, and to have a benefit-to-cost ratio of four relative to private consumption.

3. Consumer surplus, an unseen form of pleasure derived from estimated demand curves, is added. This means that CBA is not the same as GDP maximisation, nor is it aligned with classic economics in that it values some notion of internal pleasure. No distributional effects or general equilibrium aspects are involved in this calculation. Thus, this $19^{\text {th }}$-century practise is deeply inconsistent with standard macro-economics and GDP accounting; and with any empirical evidence of how people truly feel, including of how poor people value goods relative to rich people.

4. CBA applies partial equilibrium for any particular purchase or outcome, and general equilibrium for the labour market and some other aspects of the economy.

5. No consumption externalities of any kind are included. People are assumed to be an island unto themselves, with no role for jealousy or social production. 
6. When something cannot easily be valued, either it is implicitly seen as "not economic" (and hence of no value), or an attempt is made to find a willingness to pay.

Thus, CBA is a leaky bucket with elements of the 19th, 20th and 21st centuries that combines economics, 19th-century mysticism (consumer surplus), GDP accounting practises and politically convenient habits. Its main merit is that numbers come out of its procedures, and that others who follow the same procedure will obtain similar numbers. The high degree of malleability in terms of what is counted and what negotiated prices are assumed allow the CBA calculator to reach almost any conclusion.

These problems underscore why CBA has never truly become the standard for government decision-making, and political judgments are still prevalent in many areas. As we saw in the case of the Heathrow expansion, a CBA is more likely to be done to overcome a necessary hurdle within a bureaucracy than to reach an informed decision.

\section{An alternative: the WELLBY}

A very different way of looking at what government produces is to base government decision-making explicitly on the idea that the government should look after the interests of the population, measured as the wellbeing of the population. It is an old Enlightenment idea that government should care about the happiness, or wellbeing, of the population. The US Constitution, for example, characterises the pursuit of happiness as a fundamental right.

While governments in places like Bhutan have long advocated taking this ideal seriously (see Ura et al. 2012), an explicit measurement of wellbeing is needed to turn this stated ideal into a reality. As we saw above, current reality is the leaking bucket of cost-benefit analysis in which there is a strong bias towards private consumption of the rich, and against government spending and taking consumption externalities into account. To move away from that reality and towards the longstanding Enlightenment ideal, we need an actual statistical measure to base policy on. In the absence of such a measure, the ideal is just window-dressing (see Frijters et al. 2020).

The wellbeing measure proposed here is the WELLBY, which is based on the life satisfaction question. In the case of the UK, the following question is used in all the surveys conducted by the Office of National Statistics since 2011:

"Overall, how satisfied are you with your life nowadays?" 0 not at all, 10 completely.

There are many variants of this question used in other surveys, but the basic idea is to ask respondents for an evaluation of the whole of the person's life on an explicit numerical scale. A WELLBY is then one unit of life satisfaction on a $0-10$ scale 
for one person, for one year. The purpose of government is then to maximise the expected discounted stream of the WELLBYs of the country's population from now until eternity.

Readers interested in the philosophy and history of this approach, its many advocates, and various measurement issues, are referred to Frijters and Krekel (2021) or Clark et al. (2018) for lengthy discussions. Here, I only wish to briefly summarise the case.

In terms of a single equation, the aim of public policy at any moment in time is then the discounted stream of WELLBYs of the population:

$$
\sum_{t}\left(1-\rho^{W}\right)^{t} \sum_{i} S W_{i} *\left(L S_{i t}-L S_{0}\right)
$$

Here, time $t$ is in whatever unit is most convenient (years, months, minutes, decades); $\rho^{W}$ is the pure discount rate on the future, the individual counter $i$ sums over the relevant population (which will change over time); $S W_{i}$ is a non-negative weight that denotes the possibility that some people are given a higher social weight (for instance, because they are full citizens rather than joint citizens with another country); $L S_{i t}$ is the life satisfaction level expected for person $i$ at time $t$; and $L S_{0}$ is the zero point of life satisfaction, denoting the level of life satisfaction equivalent to death.

For each aspect of this basic maximand, technical standards are needed. The general proposal is that decision-making would be based on maximising the expected stream of WELLBYs. Please note that this usually will not require us to measure the stream of wellbeing. What we want instead is good evidence on the causal effects of proposed policies on wellbeing, such as evidence from experimental studies or high-quality inferential studies. We can then draw on the more than 170,000 studies that have already been done on life satisfaction (cf. Diener et al. 2018). Basically, the intention is to use this huge literature on the causes of life satisfaction to inform policy-making.

In the following, I briefly discuss the basic reasoning of this methodology; address some questions raised by public sector and academic organisations; and offer some brief remarks on the technical standards.

\subsection{Rationale}

The basic rationale is that individual responses to life satisfaction questions should be seen as a secondary form of voting. When individuals answer these questions, they are providing information about how they evaluate their life - and, thus, about what they think about their current circumstances. By analysing the circumstances associated with higher or lower evaluations, we can find out what issues matter in people's lives that can be improved by individual and government choices. More than 80 years of experience with this question has produced a social science literature of well over 100,000 articles on its determinants, and a "grey literature" of 
government reports and other non-academic publications that is easily twice as large. While the quality of this research varies widely, it provides an enormous amount of information on what matters for individuals, and thus represents an alternative to traditional cost-benefit analysis.

A good example of a real strength of this methodology is provided by the Covid-19 crisis in 2020. That crisis has led to massive changes in many different dimensions, and thus calls for the development of a methodology for making decisions about potentially painful trade-offs. How many additional lost years of life via Covid-19 deaths are worth a million more people being unemployed for another year? How many permanently damaged lungs are worth the loneliness and increased suicide rate among a billion elderly people locked up for three months? How much anxiety is alleviated due to social distancing rules, and many jobs that involve touching each other are destroyed by social distancing rules?

Standard cost-benefit analyses do not have ready answers to most of these questions, but the WELLBY methodology does have ready answers for many of the important elements (Clark et al. 2018). In brief, a year of normal life is valued at six WELLBY; a year spent unemployed costs 0.7 WELLBY a year; forced social distancing and lockdowns of the UK variety cost 0.5 WELLBY a year; and the government produces one WELLBY for about $£ 2,500$ of government revenue (Frijters and Krekel 2021). With these basic numbers alone, coupled with estimates of the economic collapse during the Covid-19 crisis and the lethality of the virus, I was able to already state that as of April 2020, that the costs of the various suppression strategies imposed by the UK government were easily 50 times higher than the possible benefits (Frijters 2020). ${ }^{1}$

Thus, one of the big selling points of the WELLBY approach is that it makes assessing difficult trade-offs relatively simple, because it provides a rough estimate of how important various things are to people that can be applied quickly when evaluating potential trade-offs.

We next discuss how this approach could be applied more generally, and which individuals within a government bureaucracy would do the calculations.

\subsection{Practices and roles}

The general idea is that all civil servants would be given some basic training in wellbeing, such that they are all aware of the basic insights on what matters a lot, and what matters only a little, for individual wellbeing and societal wellbeing. Government departments would generate their own narrative as to how their activities support wellbeing in the country as a whole, with a continuous re-setting of that narrative as departments slowly discover where they can make additional gains,

\footnotetext{
1 See also https://clubtroppo.com.au/2020/03/21/the-corona-dilemma/ for initial estimates; and here for a whole workshop on the issue: https://clubtroppo.com.au/2020/06/08/a-seminar-workshop-onwellbeing-cost-benefit-analysis-applied-to-covid/.
} 
and where they can save money on activities that, in hindsight, do not generate much wellbeing at all. There would be a gradual process of learning by individual departments and other public organisations about how they could generate more wellbeing for less money.

There would be obvious roles for universities and public intellectuals if improving the WELLBY level were taken as the goal of government. Universities would need to provide training in wellbeing-related methodology, including in the widespread use of randomised control trials to ascertain the effects of this or that factor on individual and aggregate wellbeing, as well as the many intricacies of measurement and interpretation. There would also be a role for more theoretical and "macrowellbeing" academics to discern more complex patterns, inter-dependencies and general equilibrium effects. Frijters and Krekel (2021) sketched what that could look like, but the current reality is that there are very few wellbeing theorists. Hence, there are many opportunities for ambitious young scholars in that field.

There would also be a natural role for civic society and public intellectuals in this sphere. For example, government budgets can be presented and discussed in terms of wellbeing changes in the population, using regular measurements. Journalists may be interested in the question of whether the expected increase in wellbeing from this or that new proposal is really likely to emerge. "Experts" could discuss on the news what the latest wellbeing numbers for certain groups say about the previous successes and failures of policies. In the UK, some of this activity is starting to happen via the What Works Centre for Wellbeing, which is a central hub for scientific knowledge and public discussion around wellbeing.

A focus on wellbeing has long been advocated in the UK (see Frijters et al. 2020). For example, Prime Minister David Cameron declared wellbeing to be the goal of the UK government in 2011. Moreover, in 2004, the local health care act made it mandatory for local councils to care for the wellbeing of their populations. Nonetheless, it is expected to take a long time for institutions to truly adopt these new objectives.

\subsection{Technical standards}

There are many practical and political questions that need to be addressed when actually using the WELLBY to decide whether to undertake a given policy. First, there is the question of who the affected population is. Are people who have yet to be born or to migrate to the relevant country also counted? Second, there is the question about the appropriate discount rate that governs how much future generations count relative to current generations. Third, there is the question of what stand-in measure should be used as a proxy for the WELLBY for sub-populations who cannot themselves answer questions about life satisfaction, such as babies and those who have lost their cognitive faculties. Fourth, there is the question of what level of life satisfaction is taken to be the same as death - and, hence, at what point living counts as worse than death. 
Although I have suggestions for all these technical standards (Frijters and Krekel 2021), much more important than those suggestions is the process via which technical standards would be established and could be challenged. What process would a society trust to come up with reasonable standards that produce outcomes that the society would, on balance, agree with?

The process would have to be transparent and subject to challenge; not hidden in bureaucratic processes, as is currently the case for cost-benefit standards. If public policy is to become based on the subjective opinions of the population, the key elements that are taken into account must also be visible and debatable.

One way to do this is to have an initial list of technical standards, as well as an initial list of current central estimates of the effects of various outcomes on wellbeing. The technical standards largely regulate the question of who matters. Specifically, who matters in the current and future population, and how much does death matter? That is clearly a core question of democracy and social power that can be addressed using a debatable set of standards that are occasionally adjusted by a democratic process.

It is also desirable to have an open price list with elements such as the estimated effects of a year of unemployment on wellbeing, the effects of higher nitrogen oxide in the air on wellbeing and the effects of national pride on wellbeing. Clearly, the aim is develop a price list that will reflect the actual outcomes of appeals to the public purse, and that is based on the best science available. However, as with everything scientific issue, new information is generated continuously, Thus, a transparent process is needed to determine which scientific findings are the best at some point in time.

My suggestion is to have a large, open set of prices that is, perhaps, initially compiled by a team of central civil servants, key academics and politicians who represent all of the main political parties. There would then have to be a process for reviewing and challenging these numbers.

It is crucial that the review process only engages with proposed alternatives, and does not set itself up to answer critiques. The potential for blind critique is endless. However, to allow for scientific progress to be incorporated into the process, serious alternatives to the numbers on an initial list should be considered. Hence, if there are new insights about some area, or problems with a current number, there should be a process for judging whether a specific alternative number is better than the one currently used.

The Intergovernmental Panel for Climate Change (IPCC) is a good example of this process. Its modus operandi is well-explained and critiqued by Porter et al. (2018): in the IPCC reports, there is a headline number, plus a process for challenging that number in order to get better numbers over time. It channels different scientific teams towards offering numbers. Blind critique is simply ignored.

There are, of course, questions of causality and negotiations. What effect would implementing a given policy have compared to an appropriate counterfactual? How can the costs of implementing a certain policy be minimised, and, thus, the expected 
stream of WELLBYs be maximised? Such questions will appear in thousands of contexts, and will require a slow working through of the many issues as they arise.

There are also questions of bureaucracy. How should a system in which decisions are made based on the WELLBY calculations be organised? Who should be taught what about form of wellbeing so that the available knowledge is there where it is needed? Who does the experimenting, and how do we learn from these experiments? These are difficult questions of public administration that do not have crystallised answers.

I discuss all of these questions and more in a forthcoming handbook (Frijters and Krekel 2021).

Next, I wish to outline how the WELLBY changes the nature of CBA analyses. I do so by using the same list of problems associated with CBA, and then briefly discuss how a WELLBY CBA would address these problems differently.

\subsection{Government revenue and private consumption}

As I showed earlier, traditional CBA adds up private consumption and government revenue, thus copying the approach to GDP accounting of the 1940s.

If the WELLBY is adopted as the maximand of government, then the expected life satisfaction increase due to the higher consumption can be added on top of the expected increase in population WELLBYs due to government revenue. Hence, the same comparable metric of a final outcome is used to judge both private consumption and government spending. This makes the question of whether more consumption of this or that good or service truly buys WELLBYs an empirical one. The same then holds for government revenue. While using this approach is more work than the previous practise of simply assuming that government outputs are the same inputs, it goes to the very core of the benefits and the purpose of government, and thus provides true accountability.

\subsection{The production cost of health and its value}

Since about 2010, health benefits have been counted as four times as much as the government production costs of health. Together with the previously mentioned practise of inputs-as-outputs, this basically means that government is assumed to be useless at anything but health, and to have a benefit-to-cost ratio of four relative to private consumption.

When the WELLBY is adopted, an attempt needs to be made to calculate the average number of WELLBYs bought with more general government revenue, and with particular types of spending, with the aim in principle of obtaining the same marginal benefit across all government spending. Hence, how many WELLBYs are produced with the expansion of government health services or by private spending on health becomes an empirical question. Thus, health changes need to be translated 
into WELLBY changes, which is frequently done in the wellbeing literature; i.e., Cookson et al. (2020).

\subsection{The treatment of consumer surplus}

Consumer surplus, an unseen form of pleasure derived from estimated demand curves, is added in traditional CBA. This sets CBA apart from GDP maximisation, and from classical economics, in that it values some notion of internal pleasure. Distributional effects or general equilibrium aspects are ignored in CBA. Thus, this 19th-century approach is deeply inconsistent with standard economics and GDP accounting; and with any empirical evidence of how people truly feel, or of how poor people value things relative to rich people. How would the treatment of consumer surplus change when the WELLBY is applied?

With a WELLBY, consumer surplus would have to be empirically shown via effects of consumption on life satisfaction. The effect of private income, which can be seen as a proxy for consumption, on life satisfaction is well-studied, and can provide initial answers (basically, a one log point increase in income increases yearly life satisfaction by about 0.4 , and thus buys about 0.4 WELLBY, Lindqvist et al. 2018).

\subsection{Partial equilibrium and general equilibrium}

As we saw above, traditional CBA has a pick-and-mix approach to assuming partial equilibrium or general equilibrium for different problems. Partial equilibrium is presumed for any particular purchase or outcome, and general equilibrium is assumed for the labour market and some other aspects of the economy. This is mainly done because there are simply no general equilibrium models that incorporate everything.

This is an aspect that would not change much in a WELLBY approach. While the WELLBY method does provide access to a lot of numbers that reflect the value of various forms of consumption and government production, those numbers are all estimates that come from slightly different models using different assumptions, where it is far more normal to see estimates from partial equilibrium models than more general equilibrium models.

The estimation of wellbeing effect then usually happens in a partial equilibrium manner, such as from randomised control trials that compare one group of people who get a public service (like health insurance or better police services) with a group who get standard services. Such an approach yields a partial equilibrium estimate, but then specific elements of general equilibrium, like consumer externalities, also get estimated, usually by different researchers. So the field might discover slowly over time when the general equilibrium effects are strong or weak.

Having an explicit measure of wellbeing does allow for a more natural discovery of general equilibrium effects, since it can be used to examine wellbeing changes 
between countries and over time in order to identify the effects of major changes on the macro level. However, that kind of procedure is fraught with identification issues, including measurement error, difficulties in comparing wellbeing measures over countries, and difficulties in identifying the macro effects of policies in a fast-changing environment. Thus, we should not expect progress to be particularly fast in this realm. Realistically speaking, pragmatic pick-and-mix in terms of the sophistication of the underlying theoretical structure of the socio-economic system will be a general feature of WELLBY CBA as much as it is of existing CBA.

\subsection{Consumption externalities}

In traditional CBA, there are few consumption externalities of any kind: i.e., each person is an island unto her or himself, with no role for jealousy or social production.

This radically changes with the adoption of the WELLBY as the government maximand. These consumption externalities can be estimated, which is the basis of the Easterlin Discount (see later).

\subsection{The space of goods and commodities considered}

In traditional CBA, when something cannot easily be valued, it is implicitly often seen as not economic (and hence of no value), or an attempt is made to find a willingness to pay.

Examples of elements that are difficult to value with a CBA are national pride, individual self-esteem, jealousy, anger, hurt, joy and a sense of identification with a group. While such elements are certainly studied by behavioural economists and other social scientists, they are not commonly part of CBA, because it is not easy to ask people how much they are willing to pay to, for instance, feel less jealous. Similarly, deducing a market value for the willingness to pay for being part of a group of people is far from trivial, as it is, for instance, hard in a market to deduce the degree to which anyone is part of a group.

The adoption of the WELLBY approach makes measuring these elements much easier, as it is not necessary to assume that people are aware of how much they value self-esteem, national pride, etc. The importance of those elements can be deduced by measuring over time how the wellbeing of individuals and of whole countries changes with shocks to their self-esteem, national pride, etc. This sort of measurement has been done extensively in the wellbeing literature. For instance, the hosting of the Olympics is used as identifying information for temporary local changes in national pride, as well as for its effects on wellbeing (Dolan et al. 2019). I will spell out in a later section how the found wellbeing effect of jealousy and social status can be used to change CBA methodology.

However, it is not the case that the use of the WELLBY immediately solves all issues regarding what the appropriate space of goods and commodities is. Moreover, the degree of attachment with groups remains a difficult thing to measure by 
assessing wellbeing (although there have been many attempts to do so; e.g., Pearce 2017 studied arts education classes as investments in social bonding).

However, using an empirical measure of wellbeing does have a huge advantage over using traditional CBA methods in terms of finding "missing commodities": i.e., changes in wellbeing that cannot be explained by any menu of currently observed commodities point to the existence of something unseen that is driving wellbeing changes. Thus, differences over time and between groups can be used as indicators of what the missing commodity group might be that is important for how people evaluate life.

An example of how wellbeing data indicate a missing commodity is the finding that Latino cultures, such as the cultures of Colombia and Costa Rica, are unusually happy, holding economic development constant (World Happiness Report 2019). This has led many wellbeing scholars to try to ascertain what it is about those cultures that makes the population relatively happy - which then leads to the question of whether the identified commodities can be produced elsewhere. Rojas (2020), for instance, has argued that families and friendship groups in Latin America are particularly good at creating warm social relations in which people feel free to dance, display emotions and support each other. Whether these features can be transferred to Anglo-Saxon cultures or to other cultures is very much an open question.

\subsection{Conclusion on CBA and the WELLBY}

By applying an explicit measure of what people themselves value, the most glaringly odd and inconsistent elements of standard CBA can be eliminated: i.e., we can do away with consumer surplus and inconsistent assumptions about the value created by government expenditures versus private consumption. However, not all problems disappear or are made simpler by the use of this measure. The question of the macroeconomics of wellbeing remains a very difficult one.

Next we show how a particularly important type of social externality - i.e., status and jealousy effects, also known as consumption externalities - has been valued in the wellbeing literature, and how those findings can be used to change CBA methodology.

\section{The Easterlin Discount: jealousy and envy effects of the consumption of others}

It has long been known that humans care about their outcomes relative to what others have. In the "The Theory of Moral Sentiments" of 1759, Adam Smith already rhetorically asked why humans were so busy working hard and out-doing each other. He answered himself that it was not because they cared for comforts, but, rather, that "it is our vanity that urges us on". Nowadays, we would say people care about 
their position in society; or, equivalently, about ensuring that others are jealous and envious of them, rather than the other way round.

Famously, Richard Easterlin (1974) argued that average happiness was no longer going up in the US after 1950 because although incomes were still rising, this increasing trend did not buy extra happiness, since people were not getting richer relative to their neighbours. Currently, the claims being made in this field are more sophisticated: 29 leading wellbeing researchers around the world were asked in the April 2018 World Wellbeing Panel poll whether they agreed with the statement: "Is the main effect of economic growth on national wellbeing via employment and public welfare programs?" Twenty-four out of 29 panellists agreed. The four who disagreed added only small caveats, such as that it depended on whether economic growth was inequality-neutral. Thus, the current version of Easterlin's original hypothesis is that the main WELLBY benefit of economic growth lies in increased government services, with greater private consumption providing very little additional benefit, as the individual benefit of more income is offset by more jealousy among one's neighbours and others in the country.

Just how much of the value to an individual of additional consumption is offset by jealousy among everyone else in the country is an empirical question. Richard Easterlin originally argued it was $100 \%$. The field has not yielded a consensus number, but 50\% would be at the lower edge of the estimates (see Frijters and Krekel 2021). For example, the Leiden school, which has estimated this figure since the 1970s, put it at 60\% (see the survey by Van Praag and Frijters 1999).

Therefore, one way to use the wellbeing finding that a higher consumption of others reduces the wellbeing of an individual others is to apply a discount to the benefits calculated in current CBAs to the presumed benefits of more material consumption. I call that discount the Easterlin Discount. The next question is how an appropriate discount rate can be applied; i.e., to what it should be applied.

We should be very careful in selecting the items to which we apply the Easterlin Discount. The logic is that it applies to items that convey social status, and are thus things that are exclusive; i.e., that one person can have while others cannot.

Thus, the discount can be applied to anything that individuals can brag about, including services, holidays, and all manner of social experiences. It should not, however, be applied to most government services, since they usually are equally available to all people in the same situation: i.e., they are not exclusive. An individual cannot brag about having access to that which everyone else also has access to, such as education, police protection and nature parks.

As a rule of thumb, the discount can be applied to anything in the private sphere and to nothing in the public sphere, although there are some things that governments buy that are actually only enjoyed by a privileged few (like the Royal Opera or palaces for the royals).

Table 1 shows how the Easterlin Discount could be applied to the various numbers in column 2. The table indicates that it is applied to things people could brag about; namely, consumer and producer surplus. Importantly, the discount is not applied to 
pain or to government revenue because the latter buys public goods and the first is not visible to others.

It is debatable whether the Easterlin Discount should or should not have applied to particular elements in Table 1, as one might, for example, argue for or against applying an Easterlin Discount to noise. This hinges on the question of whether noise or the absence of it is an observable exclusive status-conveying good. In principle, the goal is to have empirical evidence that addresses this question, such as surveys in which people are asked if they are jealous of the tranquillity some others buy.

However, to be operational, a default position is needed that can be applied to cases for which there is not yet good specific evidence. The default advocated is not to think of the (lack of) pain of unpleasant noise as something people brag about. Rather, the absence of irritating noise is seen as a basic right because "disturbing the peace" is not allowed by law, and because discomfort from noise is not easy to measure. However, while this might be reasonable to say of noise in the UK, this position will not hold for all countries and all periods.

Let us then give some basic numbers to show how a WELLBY and the Easterlin Discount changes the priorities in our society.

The best number we have so far on how much additional income wellbeing buys comes from an analysis of Swedish lotteries (Lindqvist et al. 2018), which states that a one-point log increase in yearly personal income buys 0.4 WELLBY. For a country with a median income of $£ 30,000$, like the UK, this essentially means that with a spread-out increase in income (everyone experiences the same absolute increase), 0.4 WELLBY can be purchased for every $£ 30,000$. In other words, $£ 75,000$ buys one WELLBY via personal consumption.

The Easterlin Discount would then have to be subtracted from this figure. If the Easterlin Discount is $50 \%, £ 150,000$ is needed to buy a WELLBY via personal consumption. If the discount is $75 \%, £ 300,000$ is needed to buy a WELLBY via personal consumption.

This outcome can be compared to government spending: one QALY that is bought via increases in life expectancy would basically buy six WELLBY (because the average life satisfaction of the healthy is about an eight, and people are probably indifferent to death at a level of two $^{2}$ ). The UK health services can then produce a WELLBY at a cost of $£ 2,500$ per unit.

Thus, with an Easterlin Discount of 50\%, marginal government expenditure can buy 60 WELLBYs for the same amount of money as individuals could buy a WELLBY with more personal spending.

2 This number comes from a study by Peasgood et al. (2018). They asked respondents about hypothetical trade-offs between differing lengths of life and the life satisfaction levels associated with that additional length of life. They found that at a life satisfaction level of two, about an equal number of respondents choose death over continued life, which denotes the point at which the marginal respondent is indifferent. 
Hence, a WELLBY orientation places far less value on personal consumption, and much more value on social relations and the things governments can provide.

\section{Conclusions}

In this short paper, I first dissected the mainstream practise of cost-benefit analysis as used by governments to decide on policy priorities, and showed that this approach is based on several inconsistencies and articles of faith, such as the assumption that social and consumption externalities are unimportant. I then introduced the WELLBY as an alternative empirical basis for cost-benefit analyses in which many of the articles of faith within the current methodology become relatively simple questions of empirical science. These questions include just how much wellbeing is created in various government programmes; how individuals are affected by the consumption of others; and what the value is of many non-market goods that are important to people, such as their children and national pride. I then illustrated the power of that methodology by discussing how knowledge of the vanity of individuals gives rise to an appropriate discount rate (the Easterlin Discount) that can be used to reduce the benefit of individual consumption relative to social benefits.

The methodology advocated in this paper is both very old and very new. It is a very old ideal to base government and public sector decision-making on that which is good for the wellbeing of the population. To truly do this using an actual measure of wellbeing based on the scientific literature is new, and will, of course, be resisted by all those who gain from the current situation. However, the explicit adoption of a wellbeing criterion at the heart of public decision-making is necessary to overcome the pro-consumption bias in current standard methods. That pro-consumption bias leads to unsustainable pressure on finite resources, and neglects many of the social and emotional aspects of humanity. We cannot go on pretending that humans are like solitary individuals quietly consuming airplane rides, not affecting anybody else nor being affected by anyone else. To take account of our interdependencies, we must move towards adopting explicit methods through which they can be measured and accounted for.

A good start towards a happier and more sustainable earth would be the adoption of the WELLBY as the object of public policy. Certainly, we can always decide to adopt something even better down the line.

\section{References}

Airports Commission 2015. Business case and sustainability assessment - Heathrow north west runway. Available at https://assets.publishing.service.gov.uk/government/ uploads/system/uploads/attachment_data/file/440315/business-case-and-sustainabilityassessment.pdf 
Boardman, A. E., D. H. Greenberg, A. R. Vining and D. L. Weimer 2017. Cost-benefit analysis: concepts and practice. Cambridge University Press.

Campbell, H. F. and R. P. C. Brown 2016. Cost-benefit analysis: financial and economic appraisal using spreadsheets. 2nd edition, Routledge.

Cesur, R., P. M. Güneş, E. Tekin and A. Ulker 2017. The value of socialized medicine: The impact of universal primary healthcare provision on mortality rates in Turkey. Journal of Public Economics 150: 75-93. https://doi.org/10.1016/j.jpubeco.2017.03.007

Clark, A. E., S. Flèche, R. Layard, N. Powdthavee and G. Ward 2018. The origins of happiness: the science of well-being over the life course. Princeton, NJ: Princeton University Press.

Cookson, R., O. Cotton-Barratt, M. D. Adler, M. Asaria and T. Ord 2020. Years of good life based on consumption and health: A practical well-being metric for economic evaluation. In Measuring the global burden of disease: philosophical dimensions, eds N. Eyal, S. A. Hurst, C. J. L. Murray, S. A. Schroeder, and D. Wikler, 126-150. Oxford University Press. https://doi.org/10.1093/med/9780190082543.003.0009

Department of Health Report. 2019. Transforming children and young people's mental health provision: a green paper. IA No: 14001, https://assets.publishing.service.gov.uk/ government/uploads/system/uploads/attachment_data/file/664442/MHGP_IA.pdf

Diener, E., R. E. Lucas and S. Oishi 2018. Advances and open questions in the science of subjective well-being. Collabra: Psychology 4(1): 15. https://doi.org/10.1525/collabra.115

Dolan, P., G. Kavetsos, C. Krekel, D. Mavridis, R. Metcalfe, C. Senik, S. Szymanski and N. R. Ziebarth 2019. Quantifying the intangible impact of the Olympics using subjective well-being data. Journal of Public Economics 177: 104043. https://doi.org/10.1016/j. jpubeco.2019.07.002

Dupuit J. 1848 translated and reprinted 1969. On the measurement of the utility of public works. In Readings in welfare economics, eds K. J. Arrow and T. Scitovsky. London: Allen and Unwin.

Easterlin, R. A. 1974. Does economic growth improve the human lot? Some empirical evidence. In Nations and households in economic growth: Essays in honor of Moses Abramovitz, eds R. David and R. Reder, 89-125. New York: Academic Press.

Easterlin, R. A. 1995. Will raising the incomes of all increase the happiness of all? Journal of Economic Behavior E Organization 27(1): 35-47.

Frijters, P. 2020. How many WELLBYs is the corona panic costing. Blog Post, https:// clubtroppo.com.au/2020/04/08/how-many-wellbys-is-the-corona-panic-costing/

Frijters, P., A. E. Clark, C. Krekel and R. Layard 2020. A happy choice: Wellbeing as the goal of government. Behavioural Public Policy 4(2): 126-165. https://doi.org/10.1017/ bpp.2019.39

Frijters, P. and C. Krekel 2021. Handbook of wellbeing policy for the UK. Forthcoming with Oxford University Press. LSE Working Paper. 338 pages.

Lindqvist, E., R. Östling and D. Cesarini 2018. Long-run effects of lottery wealth on psychological well-being. National Bureau of Economic Research No. w24667. https://doi.org/10.3386/w24667

Morrison, S. and C. Winston 2010. The evolution of the airline industry. Brookings Institution Press. 
Papanicolas, I., L. R. Woskie and A. K. Jha 2018. Health care spending in the United States and other high-income countries. JAMA 319(10): 1024-1039. https://doi.org/10.1001/ jama.2018.1150

Pearce, E. 2017. Participants' perspectives on the social bonding and well-being effects of creative arts adult education classes. Arts $\mathcal{F}$ Health 9(1): 42-59. https://doi.org/10.1080/ 17533015.2016.1193550

Peasgood, T., C. Mukuria, M. Karimi and J. Brazier 2018. Eliciting preference weights for life satisfaction: A feasibility study. Mimeo.

Porter, A. J., T. R. Kuhn and B. Nerlich 2018. Organizing authority in the climate change debate: IPCC controversies and the management of dialectical tensions. Organization Studies 39(7): 873-898. https://doi.org/10.1177\%2F0170840617707999

Rojas, M. 2020. Latin America and well-being. In Well-being in Latin America: Drivers and policies, 1-9. Springer, Cham. https://doi.org/10.1007/978-3-030-33498-7_1

Smith, A. 1759. The theory of moral sentiments (2nd edition, 1761). Strand \& Edinburgh: A. Millar; A. Kincaid \& J. Bell.

Smith, J. P. 1999. Healthy bodies and thick wallets: The dual relation between health and economic status. Journal of Economic Perspectives 13: 145-166.

Stansfeld, S. A. and M. P. Matheson 2003. Noise pollution: non-auditory effects on health. British Medical Bulletin 68(1): 243-257.

Treasury, H. M. S. 2018. The green book: Central government guidance on appraisal and evaluation. London: HM Treasury.

Ura, K., S. Alkire, T. Zangmo and K. Wangdi 2012. A short guide to gross national happiness index. The Centre for Bhutan Studies.

Van Praag, B. M. S. and P. Frijters 1999. The measurement of welfare and well-being; the Leyden approach. In Well-being: the foundations of hedonic psychology, eds D. Kahneman, E. Diener, and N. Schwarz, 413-432. New York: Russel Sage Foundation.

World Wellbeing Panel 2018. April 2018: Economic Growth, Welfare Programs \& Wellbeing. https://www.barcelonagse.eu/research/world-wellbeing-panel/survey-archive

Open Access This article is published under the terms of the Creative Commons Attribution 4.0 International License (https://creativecommons.org/licenses/by/4.0/) that allows the sharing, use and adaptation in any medium, provided that the user gives appropriate credit, provides a link to the license, and indicates if changes were made. 